\title{
Coupling Coordinative Development Model of the Economy-Society-Environment System in Some Coastal Cities of the East China Sea
}

\author{
Xiujuan Zhang ${ }^{1}$, Jiaping Wu², Jinbao Liu', Li Liu ${ }^{3 *}$ \\ 'Zhejiang Tongji Vocational College of Science and Technology, Hangzhou, China \\ ${ }^{2}$ Ocean College, Zhejiang University, Zhoushan, China \\ ${ }^{3}$ Zhejiang Shuren University, Hangzhou, China
}

Received: 20 February 2020

Accepted: 14 May 2020

\begin{abstract}
Taking the Economic-Society-Environment system as an open system with complex structures, the coordinated relationship of the three subsystems is the prerequisite for regional sustainable development. Based on statistical data from 7 cities of the East China Sea and the established evaluation system, the comprehensive development level and the coupling coordinative degrees were analysed and predicted by R/S analysis. Comprehensive development slightly increased, with a few fluctuations in Jiaxing, and all of the coastal cities were in the run-in and improving stages for basically coordinative development, except Zhoushan, and were undergoing less imbalanced development in 1995, except Jiaxing, Taizhou, Wenzhou and Ningbo. And the comprehensive development of the cities in the eastern region was higher than the other, but the coupling and coordinative degree were both $\delta$ convergent, which illustrated the less regional difference in future. However, the trend of the comprehensive and coupling coordinative development of most coastal cities in future will be opposite to that from 1995 to 2015. To realize coupling coordinative development, it is necessary to take advantage of national strategies and their own competitive advantages and then build an eco-environmental collaborative governance alliance for resource saving and establishing an environmentally friendly society.
\end{abstract}

Keywords: coupling coordinative degree, the Economic-Society-Environment system, coastal cities, urban development

\section{Introduction}

Under the background of the new normal in the economy, social and economic development in

*e-mail: casliuli@hotmail.com

coastal regions are confronted with inside and outside pressures, specifically restriction of the export-oriented economy due to the resurgence of international trade protectionism and transformation of economic development due to the structural adjustment of 'address overcapacity, reduce inventory, deleverage, lower costs, and bolster areas of weakness' during the period of China's $13^{\text {th }}$ Five-Year Plan [1-2]. Meanwhile, 
the discordance between socio-economic development, ecological carrying capacity, and serious environmental pollution has aroused wide social concerns due to the rapid social and economic development and accelerating urbanization [3]. With the implementation of 'the Belt and Road Initiatives', the coastal cities in the southeast region of China are also facing an environmental resources crisis and sustainable development problems that are affected by the intense human activities under the conditions of global change and rapid urbanization [4]. In the report of the eighteenth national congress of the Communist Party of China, the development of an ecological civilization has been strongly emphasised and incorporated into, the overall plan for advancing socialism with Chinese characteristics, the essential requirement of which is that human activities should be confined to the limits of what nature can cope with and then be properly avoided to prevent the occurrence of irreversible ecological damage [5]. Zhejiang Province, as a representative in the eastern developed provinces of China, has also been confronted with the dilemmas of land construction, economic growth and ecological degradation [6]. Therefore, the coordinative development of an ecological environment and socio-economy is a necessary means of achieving the objective of the new urbanization in coastal regions of the East China Sea, as an important part of the Eastern Ocean Economic Circle and Yangtze River Delta Economic Circle, and maintaining sustainable and sound development. It is important to establish an evaluation model for the Economic-Society-Environment system of the 7 coastal cities and then analyse the trends of their coupling coordinative development.

Due to the synthesis of the research on the coordination of the socio-economic system, many scholars in different academic disciplines, such as ecology, geography, economics, and management, have performed studies from different perspectives. Foreign research on the interaction of the socio-economy and the environment is mature. As early as 1987, the United Nations Commission on the environment and development defined the term 'sustainability' and popularized the idea that sustainable development meets the needs of the present without compromising the ability of future generations to meet their own needs [7]. Then, the scope and intensity of coupled societies and the economy dramatically increased. It was found that there is a mutual relationship between economic development and resource environment from competition to adaptation, which forms an inverted U-shape known as the Environment Kuzlitz Curve [8]. All human- related resources are embedded in complex social-ecological systems, which are composed of multiple subsystems and internal variables within these subsystems [9]. Later, foreign scholars began to focus on subsystems coordination issues with many quantitative methods, such as the Input-Output model
[10], ecological footprint [11-13], energy analysis [14-15], to construct an integrative framework and comprehensive methods to understand the complexities of society-economy interactions and determine the interaction mechanisms and influencing factors. Later, as the contradiction between economic development and the ecological environment in China became acute, Chinese scholars began to apply these methods and models in multidiscipline. Some scholars focused on the evaluation index system of the ecology-economy system [16-19], while others paid attention to the coordinative development in different regions, provinces, or ecological function areas [20-25]. Today, empirical research on the comprehensive framework of ecology, economy and society is less popular, not to mention the dynamic analysis of the coupling development and the spatial heterogeneity of the composite system. Therefore, based on the statistical data from 7 cities, we established the evaluation system of the Economy -Society-Environment system to assess the coupling coordinative development level of the whole system from 1995 to 2015 in the 7 coastal cities of the East China Sea in temporal and spatial dimensions and predict the trend of their coupling coordinative degree via $\mathrm{R} / \mathrm{S}$ analysis, which provided a scientific basis and theoretical support for the sustainable development of all 7 coastal cities.

\section{Material and Methods}

\section{Study Area}

Zhejiang Province is located in the southeast of China and has a long coastline of $1.8 \times 10^{3} \mathrm{~km}$ [26] and a total maritime area of $2.6 \times 105 \mathrm{~km}^{2}$ [27]. There are 7 coastal cities among the 11 prefecture-level cities of Zhejiang Province, including Hangzhou, Jiaxing, Shaoxing, Ningbo, Zhoushan, Taizhou, and Wenzhou. Due to the central location of the eastern coastal developed cities in China, and the T-type junction of the Yangtze River Basin, Zhejiang Province has superior geographic conditions and regional and international strategic transportation. Since the 1980s, when the world economy began to focus on the AsiaPacific region, Zhejiang Province, as the bond of East Asian economic development, attracted domestic and foreign investment and developed an industrial economy. However, Zhejiang Province has recently been confronted with the dilemma of being caught between economic acceleration and environmental protection. Whilst the provincial government has taken some measures, such as building monitoring stations and implementing 'environmental action', the ecological problems caused by its industrial structure with high energy consumption and high emissions has not been fundamentally solved. 


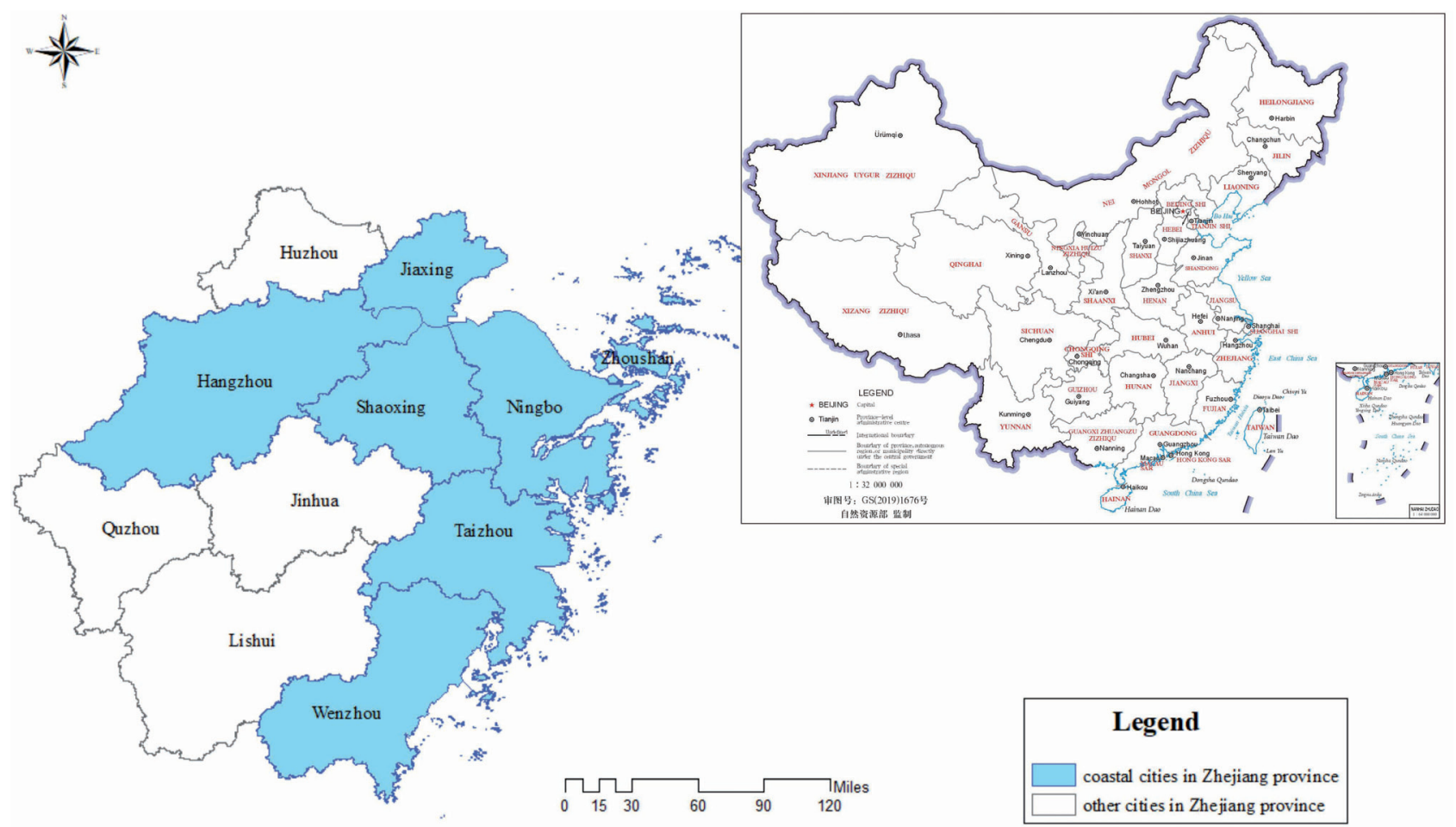

Fig. 1. Location of the study site.

\section{Model Description}

\section{The Coupling Coordinative Degree Model}

According to the scientific nature of index selection, the completeness of the index system, and the availability of data, referring to the evaluation index in 'China Development Report 2015' [28], the evaluation system shown in Table 1 was established to access the comprehensive development level of the whole coupling system and its subsystems in the 7 coastal cities of the East China Sea in the period 1995-2015. The data were derived from 'China Statistical Yearbook', 'China City Statistical Yearbook', 'China Marine Statistical Yearbook', 'Zhejiang Statistical Yearbook', 'Hangzhou Statistical Yearbook', 'Jiaxing Statistical Yearbook', 'Shaoxing Statistical Yearbook', 'Ningbo Statistical Yearbook', 'Zhoushan Statistical Yearbook', 'Wenzhou Statistical Yearbook', and 'Taizhou Statistical Yearbook'. Due to the different dimensions of the original data, the data were standardized by the difference method to ensure comparability between them. The index (xi), which is better when the value is bigger, can be defined as the positive indicator, and vice versa as the negative indicator.

$x_{i}^{\prime}= \begin{cases}\frac{x_{i}-\min \left(x_{i}\right)}{\max \left(x_{i}\right)-\min \left(x_{i}\right)} & \text { if } x_{i} \text { is positive indicator } \\ \frac{\max \left(x_{i}\right)-x_{i}}{\max \left(x_{i}\right)-\min \left(x_{i}\right)} & \text { if } x_{i} \text { is negative indicator }\end{cases}$

$x_{i}$ ' represents the index values in each index layer (i) that has been standardized by the difference method.
Therein, $\max \left(\mathrm{x}_{\mathrm{i}}\right)$ and $\min \left(\mathrm{x}_{\mathrm{i}}\right)$ are the maximum and minimum values of $x i$ in each index layer(i).

Based on the capacity coupling coefficient model in physics, the coupling degree model of the economicsociety-environment system [29] was constructed, namely,

$$
C=\left[\frac{f_{1}(x) f_{2}(x) f_{3}(x)}{\prod\left(f_{i}+f_{j}\right)}\right]^{1 / 3} \quad(i \neq j, i, j \in[1,3])
$$

$\mathrm{C}$ represents the coupling degree. Therein, $\mathrm{f}(\mathrm{x})$ is the evaluation function of the economic subsystem, the society subsystem, and the environment subsystem, which are the product of standardized values of the three subsystems, and the weights of the indices in the three subsystems calculated by the entropy method, respectively.

As for the multi-regional comparison, the coupling degree is difficult to reflect the coordination of the whole coupling system, which leads to the inconsistence with the actual situation. Therefore, we introduced the coordinative degree model [30] to access the development of mutual coordination between the economic, society and environment subsystems in the 7 coastal cities. The formula is,

$$
D=\sqrt{C \times T}, T=\alpha f_{1}(x)+\beta f_{2}(y)+\gamma f_{3}(z)
$$

$\mathrm{D}$ represents the coordinative degree, which is between 0 and $1 . T$ is the comprehensive value of the whole coupling system. $\alpha, \beta$ and $\gamma$ are the weights of the 
Table 1. Evaluation system of the Economic - Society - Environment of the 7 coastal cities.

\begin{tabular}{|c|c|c|}
\hline Target Layer & Criterion Layer & Index Layer \\
\hline \multirow{10}{*}{ Economy Subsystem } & \multirow{3}{*}{ Economic vigour } & Per capital GDP growth rate \\
\hline & & GDP index \\
\hline & & Foreign capital \\
\hline & \multirow{4}{*}{ Economic structure } & Percentage of service industry increment in GDP \\
\hline & & Percentage of fishery increment in GDP \\
\hline & & Percentage of household consumption in GDP \\
\hline & & Percentage of high-tech production in industry \\
\hline & \multirow{3}{*}{ Economic benefit } & Percentage of fiscal revenue in GDP \\
\hline & & Social labour productivity \\
\hline & & GDP per area \\
\hline \multirow{10}{*}{ Society Subsystem } & \multirow{2}{*}{ Urbanization } & Urbanization rate \\
\hline & & Engel coefficient \\
\hline & \multirow{2}{*}{ Land } & Per capita living space \\
\hline & & Coverage rate of green area in developed area \\
\hline & \multirow{2}{*}{ Transportation } & Turnover volume of waterway freight traffic \\
\hline & & Per capita area of paved roads in city \\
\hline & \multirow{2}{*}{ Tourism } & Number of tourists \\
\hline & & Percentage of tourism income in GDP \\
\hline & \multirow{2}{*}{ Education } & Numbers of students in senior schools \\
\hline & & Total collections of books in public libraries \\
\hline \multirow{9}{*}{ Environment Subsystem } & \multirow{3}{*}{ Environment quality } & Per capita public green area \\
\hline & & Per capita arable area \\
\hline & & Per capital water resource \\
\hline & \multirow{3}{*}{ Environment pollution } & Industrial waste water discharge \\
\hline & & Volume of industrial solid waste produced \\
\hline & & Industrial waste gas emission \\
\hline & \multirow{3}{*}{ Environment management } & Rate of industrial solid waste utilized \\
\hline & & Ration of waste water treated \\
\hline & & Ratio of consumption wastes treated \\
\hline
\end{tabular}

three subsystems calculated by the analytic hierarchy process, which are $0.44,0.17$ and 0.39 , respectively.

\section{$R / S$ Analysis}

$\mathrm{R} / \mathrm{S}$ analysis was firstly proposed by Hurst, and then further improved by Mandelbrot and Wallis into a fractal theory of time series [31-32]. The basic principle is that there is a Hurst phenomenon for the time series $\left[\varepsilon_{t}\right](1 \leq t \leq T)$, if the relationship between the range $\mathrm{R}$ and the standard deviation $\mathrm{S}$ is $\mathrm{R} / \mathrm{S} \propto \mathrm{T}^{\mathrm{H}}$ [33]. Thereinto, the range $\mathrm{R}$ of the variance $\mathrm{D}(\mathrm{t}, \mathrm{T})$ and the standard deviation $\mathrm{S}$ of $\varepsilon_{\mathrm{t}}$ are,

$$
\begin{gathered}
\mathrm{R}=\max \mathrm{D}(\mathrm{t}, \mathrm{T})-\min \mathrm{D}(\mathrm{t}, \mathrm{T}) \\
\mathrm{D}(\mathrm{t}, \mathrm{T})=\sum_{\mathrm{t}=1}^{\mathrm{T}}\left(\varepsilon_{\mathrm{t}}-\bar{\varepsilon}\right) \\
\mathrm{S}=\sqrt{\frac{1}{\mathrm{~T}} \sum_{\mathrm{t}=1}^{\mathrm{T}}\left(\varepsilon_{\mathrm{t}}-\bar{\varepsilon}\right)^{2}}
\end{gathered}
$$

$\mathrm{H}$ is the Hurst exponent, which can be calculated using the least squares fitting method in the double logarithmic coordinate system (ln $\mathrm{n}, \ln (\mathrm{R} / \mathrm{S}))$. If $\mathrm{H}=0.5$, it indicates that the time series is completely random; if $0<\mathrm{H}<0.5$, it indicates that there is a negative tendency in the time series. The closer the $\mathrm{H}$ value 
is to 0 , the more obvious the negative tendency is; if $0.5<\mathrm{H}<1$, it indicates that the time series has a positive trend. The closer the $\mathrm{H}$ value is to 1 , the more obvious the positive trend.

\section{$\delta$ Converge Test}

The $\delta$ converge test is used to analyse the deviation of the regional coupling and coordinative degree from their average and the dynamic process, which can be calculated by

$$
\mathrm{CV}=\sqrt{\frac{\sum_{\mathrm{i}=1}^{\mathrm{n}}\left(\mathrm{c}_{\mathrm{i}}-\overline{\mathrm{c}}\right)^{2}}{\mathrm{n}}} / \overline{\mathrm{c}}
$$

$\mathrm{CV}$ is the index of $\delta$ converge test, the $\mathrm{c}_{\mathrm{i}}$ is the coupling degree or the coordinative degree of one coastal city in the specific year, $\mathrm{n}$ is the total number of the cities, and $\bar{c}$ is the average of the coupling degree or the coordinative degree of all 7 coastal cities in the specific year. The larger $\mathrm{CV}$ is, the larger the gap of the coupling degree of the coordinative degree in different regions. If the $\mathrm{CV}$ is in a downward trend, it means that there is a $\delta$ convergence in these regions.

\section{Results and Discussion}

Comprehensive Development Level of the Economic-Society-Environment System and Its Subsystems

In Fig. 2, for Hangzhou City, the average comprehensive evaluation index of the whole system was 0.517 with an annual growth rate of $2.16 \%$, which continuously increased from 1995 to 2015 and represented the better development of the whole system in most coastal cities. Before 2009, the development of the Environment subsystem was better than that of the other subsystems, while development of society has exceeded that of the others since then. As for Jiaxing City, the comprehensive evaluation index increased by $3.39 \%$ from 1995 to 2015 with an average value of 0.503 , but some fluctuations occurred in 1997, which were caused by the decline in the economic and environment subsystems. During the period 1995-2003, the development of environment and economic subsystems was better than the society subsystem, while the society subsystem exceeded the economic subsystem in 2004 and the environment

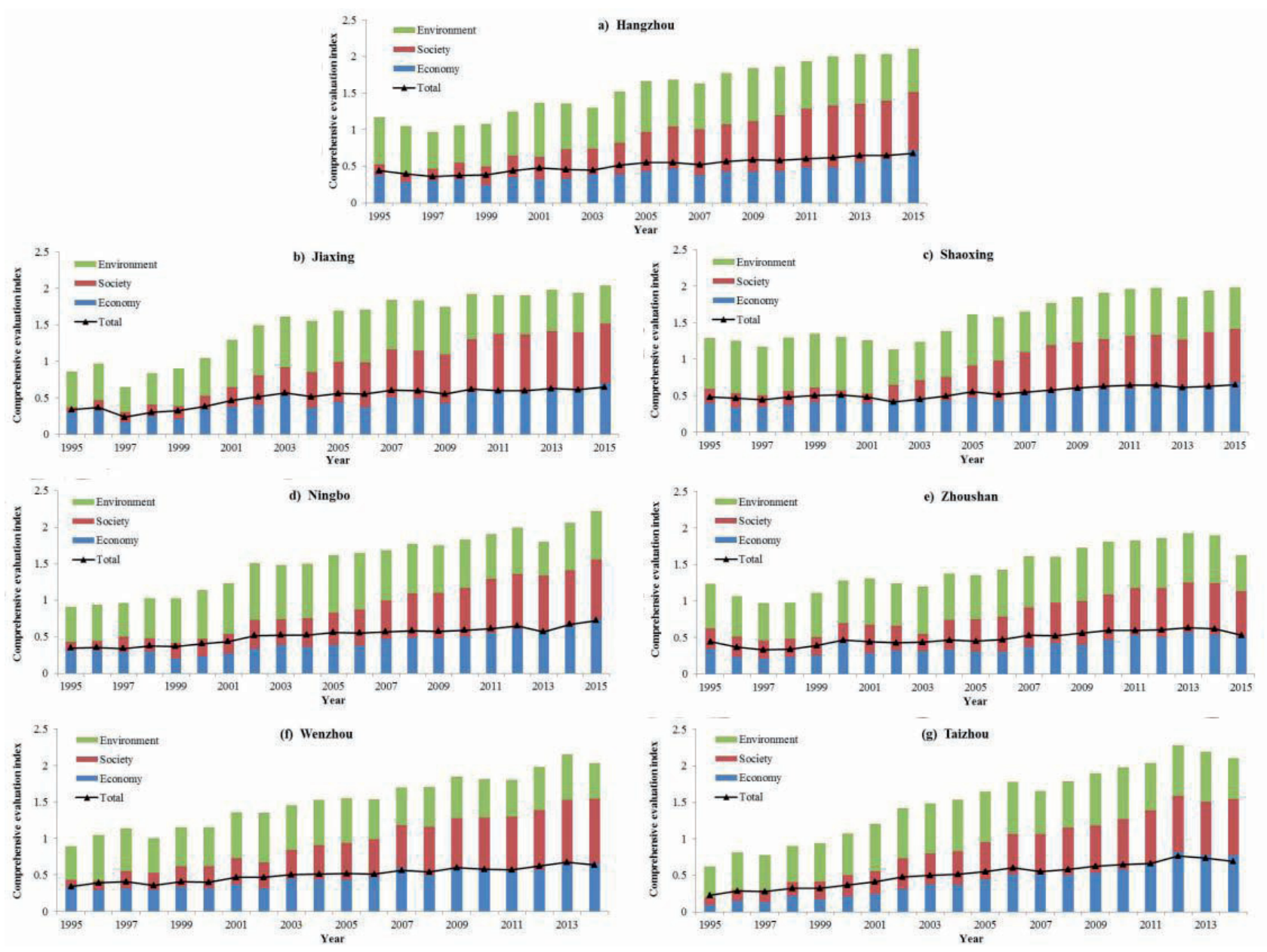

Fig. 2. Comprehensive evaluation index of the Economic-Society-Environment system and its subsystems in 7 coastal cities from 1995 to 2015. a) Hangzhou City, b) Jiaxing City, c) Shaoxing City, d) Ningbo City, e) Zhoushan City, f) Wenzhou City, and g) Taizhou City. 
subsystem in 2009. As for Shaoxing City, the comprehensive evaluation index of the whole system rose by $1.51 \%$ from 1995 to 2015 with an average value of 0.537 , and there were some changes during the period of 1995-2002 that were mainly caused by the anomalous change of environmental development in Shaoxing together with the effect of changes in the development of the society and economic subsystems. As for Ningbo City, the average comprehensive evaluation index of the whole system was 0.515 , and steadily increased by $3.76 \%$ from 1995 to 2015, except for a subtle declined value in 2013 due to an anomaly in the environment subsystem. Since 2005, the evaluation index of the environment subsystem began to decline, and the society subsystem became predominant after 2010. As for Zhoushan City, the comprehensive evaluation index first fluctuated and then kept at continuous growth, with an annual growth rate of $0.93 \%$ and an average value of 0.485 from 1995 to 2015 , which was the weakest development of the whole system of 7 coastal cities of the East China Sea. Especially before 2005, the development of the three subsystems was in a state of fluctuation. Throughout the whole research period, the development of the environment subsystem was better than the other ones, while development of society rapidly increased since 2004. As for Taizhou City, the development of the whole system was in a stationary phase compared with the other cities. The average comprehensive evaluation index was 0.506 with the annual growth rate of $6.07 \%$ from 1995 to 2014, which was the fastest in all 7 coastal cities. Subtle changes in the environment and economic development had occurred since 2007, which showed the breaking-in period between the rapid economic development and the environmental protection. As for Wenzhou City, the development of the whole system was in a relatively stationary phase, with an annual growth rate of $3.28 \%$ and the average value of 0.503 , while the development of the three subsystems was variable from 1995 to 2014. Before 2006, development of the environment subsystem was the best, and development of society became the best after 2006 .

Coupling Coordinative Development Level of the Economic-Society-Environment System

The coupling degree of the Economic-SocietyEnvironment system in these cities, which has been calculated by Equation 2 (Fig. 3), basically increased from 0.4 to 0.5 , which indicated the run-in and continuously improving stage between the ecological environment and the socio-economic development, except for Shaoxing City, which drastically fluctuated in 2000 and 2001. The relationship between the Economic, Society, and Environment subsystems of Shaoxing was not very close, with less reliance on each other. In 2000, the coupling degrees of Hangzhou, Ningbo, Wenzhou, Jiaxing, Shaoxing, Zhoushan, and Taizhou were $0.483,0.46,0.488,0.469,0.39,0.48$, and 0.472 , respectively, while there were obvious fluctuations in most of the coastal cities except Zhoushan before 2000. Due to the one-sided pursuit of GDP growth and heavy industry development without the consideration of environmental protection, a series of ecological environment destruction and pollution events had occurred, leading to peoples' environmental protection consciousness. Since then, the coupling development of the Economic-Society-Environment system in all of the coastal cities had been improved because of the good opportunity for the socio-economic development and the ecological restoration.

During the period of 1995-2015, all coordinative degrees calculated by Equation 3 (Fig. 4) remained between 0.3 and 0.6 , and the average coordinative degree of each coastal city was 0.493 , which indicated the basically coordinative development of the Economic -Society-Environment system, and the increasing trend

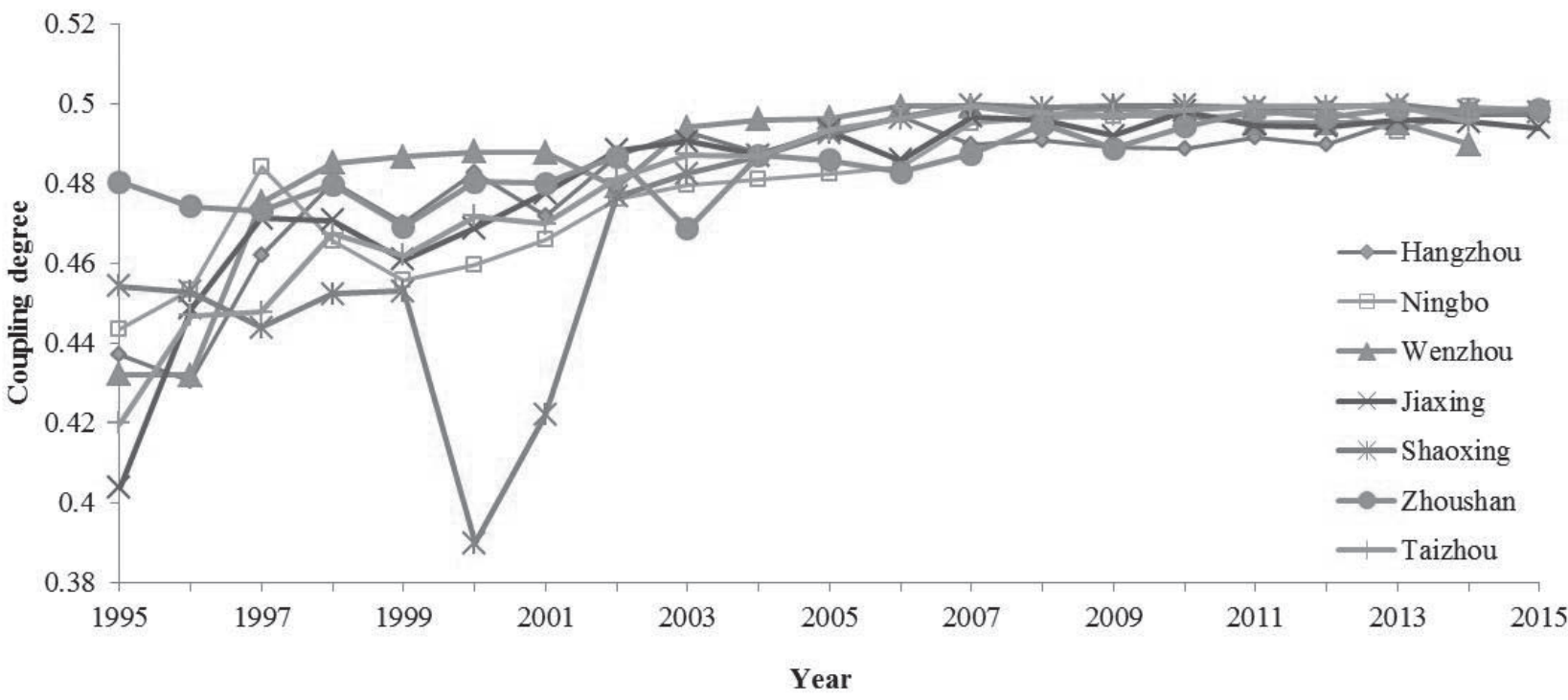

Fig. 3. Coupling degree of the Economic-Society-Environment system in 7 coastal cities from 1995 to 2015. 


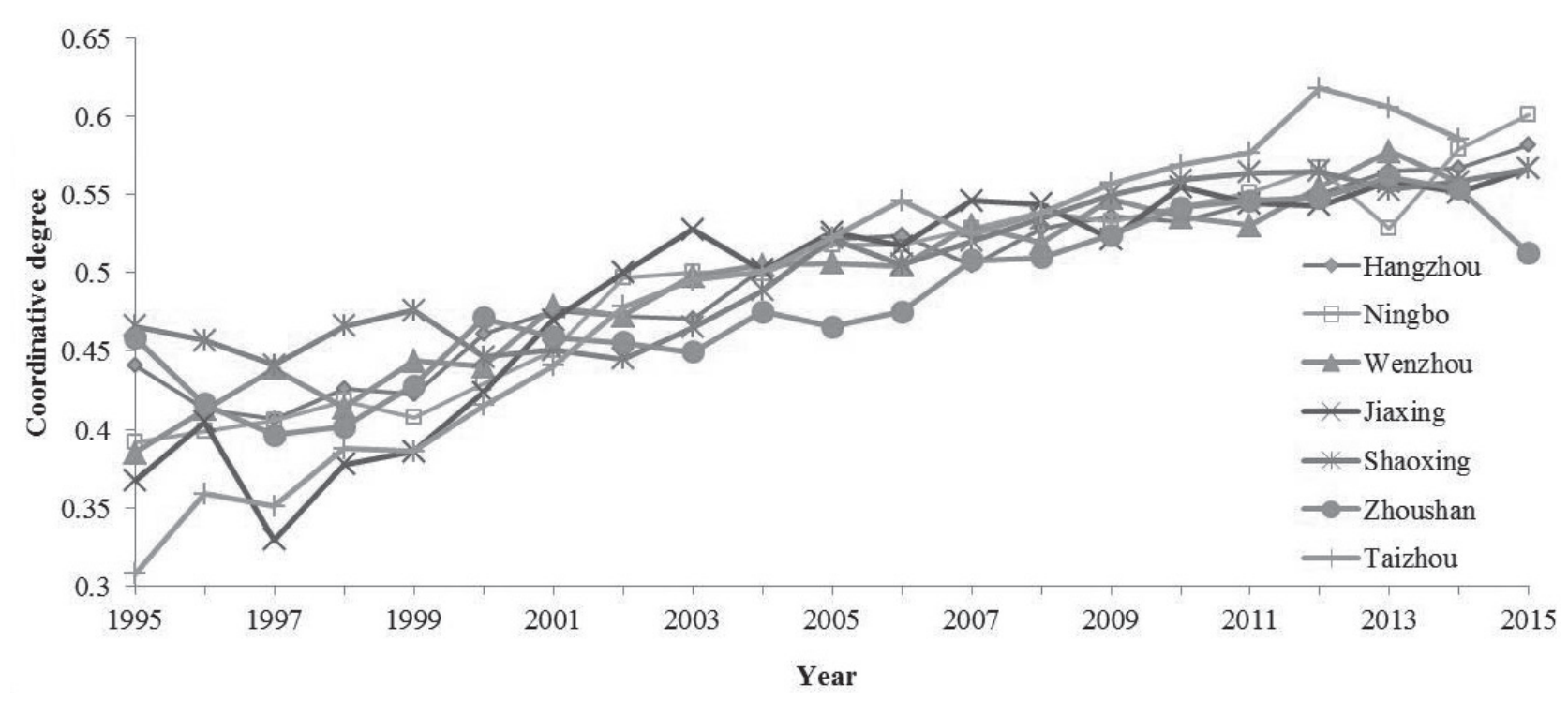

Fig. 4. Coordinative degree of the Economic-Society-Environment system in 7 coastal cities from 1995 to 2015.

showed potential development in the future. Before 2000, the coordinative degrees of Shaoxing, Hangzhou, Zhoushan, Ningbo and Wenzhou were higher, and there were obvious fluctuations in most cities except Ningbo and Wenzhou, which were ascribed to the imbalance in socio-economic development and environmental carrying capacity in the initial developing phase. The coordinative development of the three subsystems in most of the coastal cities was in rising and stable stages since 2000, with small fluctuations in the period of 2000-2006 and 2012-2015, which illustrated that there was a better coordinated relationship of socio-economic development and environmental protection in these cities due to the superior technology, good support policy and abundant natural resources.

As for the comparative multi-regional study, only considering the coupling degree might lead to difficulty in reflecting the overall coordination level of the complex system, and the bias between the research results and the actual situation. Hence, on the basis of the coupling degree, the coordinative degree should be considered together (Fig. 5). According to the situation of the coupling coordinative degree in all 7 coastal cities and the standard for the classification of coupling degree, for 1995, 2005 and 2014, all of the coastal cities stayed in the antagonistic phase, which meant that the

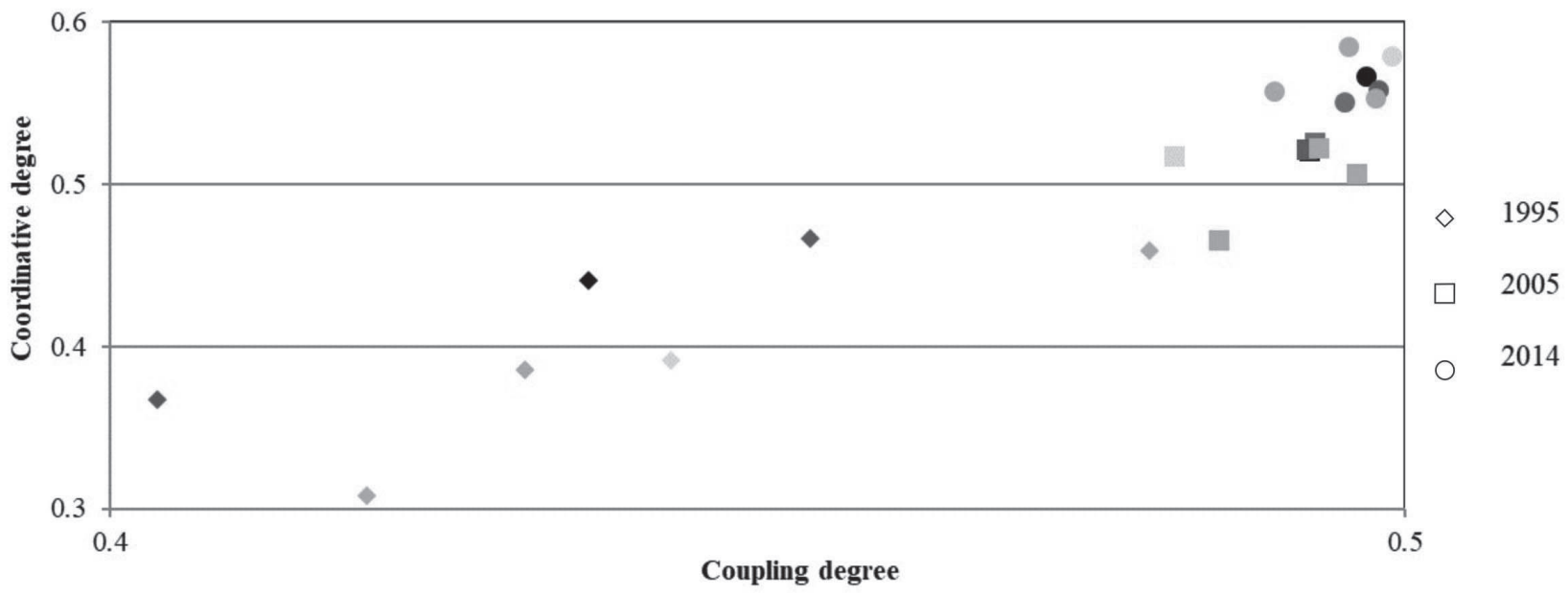

Fig. 5. Characteristics of the coupling degree and coordinative degree of the Economic-Society-Environment system in 7 coastal cities in 1995, 2005, and 2014. (1) According to the relevant literature (Wang and Tang, 2015; Xie, Chen and Li, 2016; Sun et al., 2017; Bi, Yang and Liu, 2017), the coupling degree is between 0.2 and 0.5 , which is classified into the antagonistic phase. (2) The coordinative degree is $0.2-0.4,0.4-0.5$, and $0.5-0.6$, which is classified into moderate imbalance, low imbalance and basic coordination, respectively. (3) Different colours represent different cities, Black-Hangzhou, Grey-Ningbo, Green-Wenzhou, Purple-Jiaxing, Blue-Shaoxing, Orange-Zhoushan, and Light Blue-Taizhou; (2) due to the missing data for Wenzhou and Taizhou in 2015, the coupling degree and the coordinative degree of the Economic-Society-Environment system in 2014 were chosen for comparison to 1995 and 2005. 
ecological environment might be slightly damaged and the environmental carrying capacity decreased with the rapid socio-economic development. In 1995, the three subsystems of Jiaxing, Taizhou, Wenzhou and Ningbo were moderately imbalanced, while these of the other three cities were less imbalanced. In 2005, the three subsystems of all of the coastal cities were basically coordinative, while these of Zhoushan in 2005 were slightly imbalanced. All of the coastal cities except Zhoushan have fully seized the opportunity of social-economic development and strengthened environmental protection, which have significantly improved the coupling coordination degree. In 2014, the three subsystems of all the coastal cities were basically coordinative, which illustrates the growing trends of the coupling coordinative development of the EconomicSociety-Environment system in all cities.

\section{Trends in the Coupling Coordinative Degree of the Economic-Society-Environment System}

The $\mathrm{R}^{2}$ values mean that the prediction accuracy of the $\mathrm{R} / \mathrm{S}$ analysis is high and the fitting effect is good. In Fig. 6, as for the R/S analysis on the comprehensive evaluation index, the values of $\mathrm{H}$ for Hangzhou, Jiaxing, Shaoxing, Ningbo, Zhoushan, Wenzhou, and Taizhou were $0.3387,0.3417,0.308,0.3492,0.356,0.3421$, 0.3614 , respectively, which were all below 0.5 . The comprehensive evaluation indices of some cities, such as Zhoushan, Taizhou and Wenhou, decreased since 2013. In addition, the trend of comprehensive development in all of the coastal cities in the future will be opposite that from 1995 to 2015, which indicates that comprehensive development in all of the coastal cities will follow a decreasing trend. However, the $\mathrm{H}$ values are all closer to 0.5 , which means the decreasing trend is not obvious. As for the R/S analysis on the coupling degree, the values of $\mathrm{H}$ for Hangzhou, Jiaxing, Shaoxing, Ningbo, Zhoushan, Wenzhou, and Taizhou were 0.4827, 0.4345, $0.269,0.3382,0.329,0.5386$, and 0.4225 , respectively, which were all less than 0.5 (except Wenzhou). These data show that the coupling degree of all cities except Wenzhou will follow an inconspicuously decreasing trend. However, the value of $\mathrm{H}$ for the coupling degree of Wenzhou was close to 0.5 , which indicated that the increasing trend is not obvious and might be unsustainable under the abnormal changes in external influence factors in the future. While the negative trend of the coupling degree in Shaoxing was relatively obvious, more attention should be paid to adjusting the mutual development between the socio-economic growth and the environmental carrying capacity. As for the R/S analysis of the coordinative degree, the values of $\mathrm{H}$ for Hangzhou, Jiaxing, Shaoxing, Ningbo, Zhoushan, Wenzhou, and Taizhou were 0.3554, 0.3587, $0.3014,0.3485,0.3568,0.3672$, and 0.3721 , respectively, which was similar to the comprehensive evaluation index in all coastal cities. To guarantee the coordinative development of the Economic-Society-Environment system, importance should be attached to ecological protection and environmental improvement on the basis of economic development, infrastructure construction and education promotion.

\section{Spatial Heterogeneity and $\delta$ Converge Tests}

The comprehensive evaluation indices of the Economic-Society-Environment system slightly increased in most coastal cities, with a few fluctuations in Jiaxing, while a decreasing trend in the comprehensive development occurred in Zhoushan, Taizhou and Wenzhou since ca. 2013. Taking the three subsystems into consideration, social development in Jiaxing, especially the public services and infrastructure construction, is better than in other cities, but has brought pressure on the environment and resulted in the decrease of the environment subsystem. As for Zhoushan, with a good ecological environment but relatively weak industry, its ecology subsystem is higher than that of other cities while a descending trend occurred recently. Economic development in Taizhou and Wenzhou was significantly higher than the other cities, but high pollution and energy consumption industries brought large pressure to the ecological environment, which results in negative effects on the coordinative development in the two cities.

To estimate whether there was spatial heterogeneity or not, the spatial distribution of the comprehensive development level in all of the coastal cities (Fig. 7) showed that there were obvious differences in the comprehensive development of 1995, 2005, and 2014. Overall, the comprehensive development levels of each coastal city increased from 1995 to 2014. Hereinto, the comprehensive development level of each city was lower than in 2005 and 2014 with significant regional differences, which manifested that the comprehensive development of the cities in the eastern region was higher than the other and the comprehensive development level of Taizhou was the lowest in all of the coastal cities in 1995. However, the comprehensive development of all of the coastal cities in 2005 and 2014 was almost in the same level, except for Zhoushan in 2005. The coupling coordinative degree model portrays the statues among economic, society, and ecology subsystems, and provides a holistic view of the evolution trajectory for combing sustainable theory with the actual situation [34]. As for the coupling coordinative development, all of the coastal cities were in the runin and improving stage with basically coordinative development in 2005, except for Zhoushan, and 2014, while with the basically coordinative development in 1995, except Jiaxing, Taizhou, Wenzhou and Ningbo. During the period of 1995-2015, the coupling degree of the Economic-Society-Environment system in these cities basically increased, except Shaoxing City, which drastically fluctuated in 2000 and 2001. The increasing trend of most coordinative degrees with few fluctuations showed potential development in the future. Due to the 

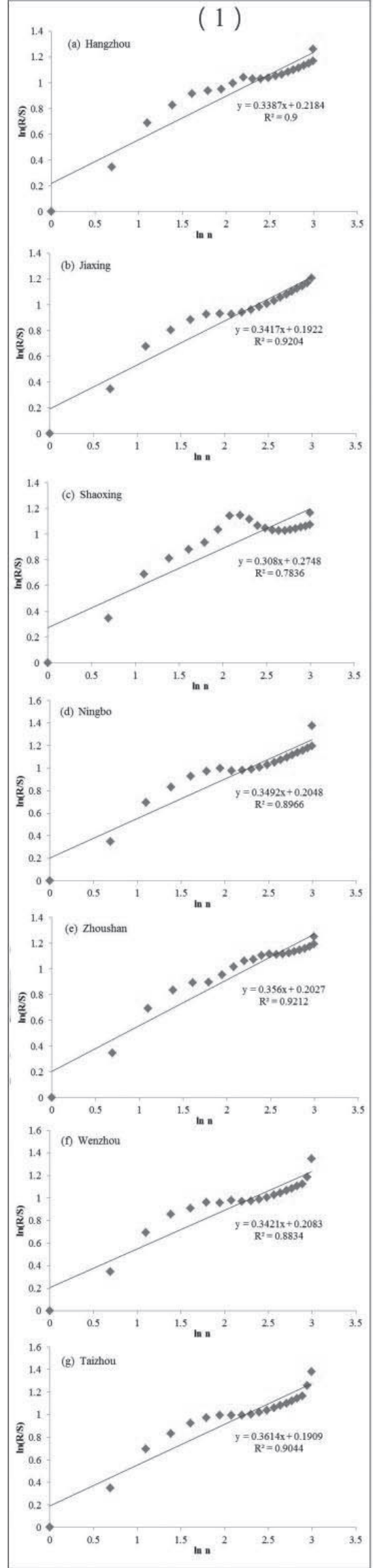
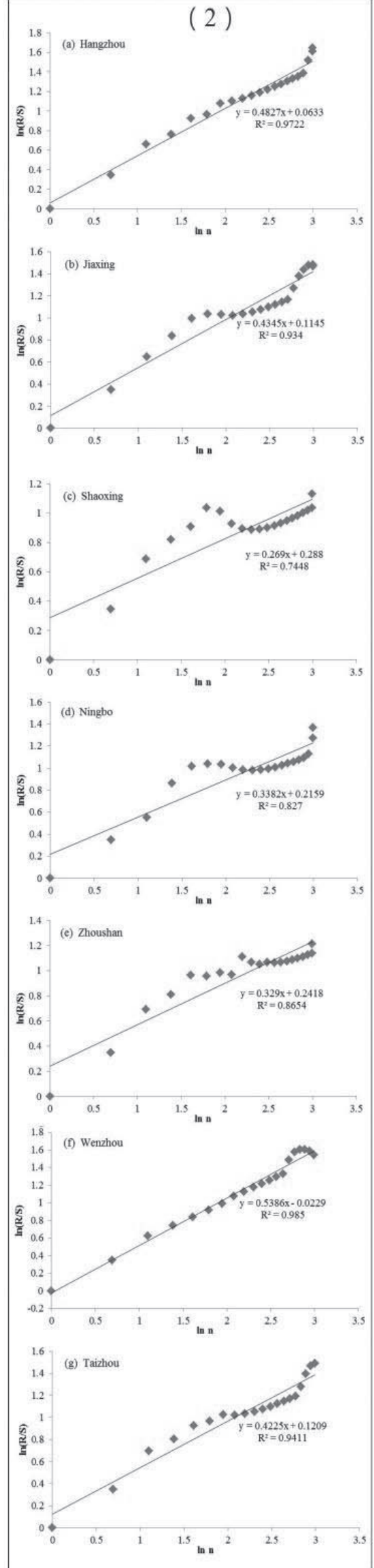
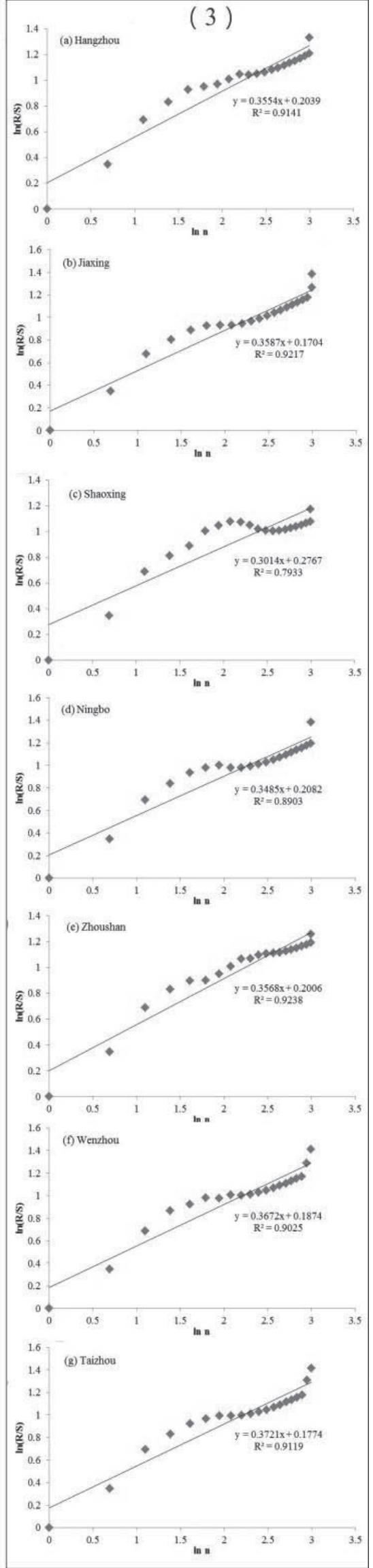

Fig. 6. R/S analysis of the comprehensive evaluation index, coupling degree, and coordinative degree of the Economic-SocietyEnvironment system in 7 coastal cities from 1995 to 2015. (1) Comprehensive evaluation index, (2) Coupling degree, (3) Coordinative degree. The values of $\mathrm{H}$ are the coefficients of the linear regression equations. 


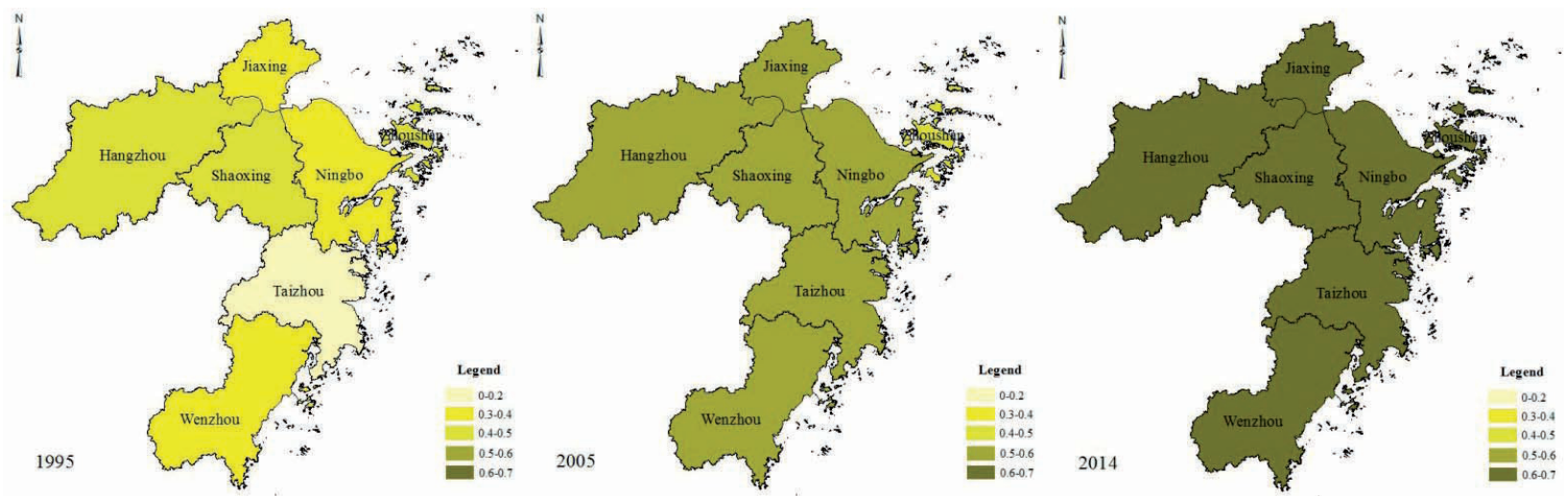

Fig. 7. Distribution of the comprehensive development level of the Economic - Society - Environment system in 7 coastal cities in 1995 , 2005 , and 2014.

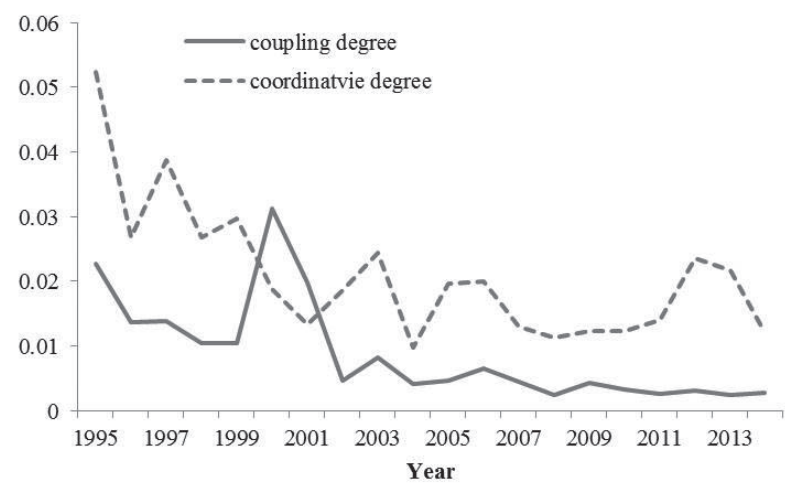

Fig. 8. Estimation of the convergence of the coupling and coordinative degree of the Economic-Society-Environment system in 7 coastal cities from 1995 to 2014.

differences in the coupling degree and coordinative degree of all 7 coastal cities, the $\delta$ converge test was chosen to measure the regional differences in the coupling and coordinative degrees (Fig. 8).

As for the coupling degree, the $\delta$ values first decreased from 0.052 in 1995 rapidly and then slightly decreased to 0.006 in 2014 after 2002, although there were mutant values because of the drastic fluctuations of Shaoxing in 2000 and 2001, which illustrated that the coupling degree was $\delta$ convergent. However, for the coordinative degree, the $\delta$ values fluctuated continuously, in spite of basically descending from 0.13 in 1995 to 0.021 in 2014, which indicated that the coordinative degree was also $\delta$ convergent, although more obvious differences among the coordinative degrees of these cities can be observed compared to the coupling degrees.

\section{Conclusions}

This study provides an updated coupling coordinative degree model for quantifying sequential coastal cities development in multi dimensions based on the evaluation system of the Economic-SocietyEnvironment. Furthermore, this model explored the interdependencies and trends among the integrated the Economic-Society-Environment from 1995 to 2015, and proved to be viable for characterizing the socioeconomic and environment dynamics of the 7 coastal cities in the East China Sea. Comprehensive development slightly increased in most coastal cities, with a few fluctuations in Jiaxing, and all of the coastal cities were in the runin and improving stages with moderately coordinative development in 2005 and 2014, except Zhoushan, and basically coordinative development in 1995, except Jiaxing, Taizhou, Wenzhou and Ningbo. However, the trend of the comprehensive and the coupling coordinative development in most of the coastal cities will decline, which is not obvious. The results indicate the importance of a low-carbon and circular economic development pattern under the pressure of natural resources reduction and rapid urbanization. For the environmentally backward cities, such as Wenzhou and Jiaxing, the rapid industrial development and the disorderly spread of cities have exerted great pressure on the ecological environment. In the future, it is urgent to change the economic development mode and relieve the pressure on the environment, including controlling energy consumption, strictly monitoring waste discharge, improving the comprehensive utilization rate of solid waste, and increasing investment in environmental protection and public facilities. Socialeconomic backward cities, such as Zhoushan, should focus on promoting economic development and urban construction, including raising the proportion of the urban population and employment in secondary and tertiary industries, improving infrastructure and public services, and increasing the local financial income, to accelerate the process of social-ecological development and then narrow the gap with other cities as soon as possible.

Additionally, to realize the coupling coordinative development of all 7 coastal cities, it is necessary to take advantage of national strategies, such as the HangzhouJiaxing-Huzhou Economic Zone, national innovation 
development of marine economy in Zhoushan and Ningbo, Free Trade Zone Strategy in Zhoushan, and Innovation development of Integrated Costal Management in Wenzhou, giving full play to their own competitive advantages in ecological resources, traffic location, and economic foundations. In the perspective of sustainable eco-economic development, the transformation of the economic development mode should be considered to promote the policy of energy conservation and emission reduction by upgrading industrial technology. Meanwhile, all 7 coastal cities of the East China Sea should enhance their cooperation on the basis of socio-economic development to share resources and complement each other's advantages and then build an eco-environmental collaborative governance alliance to construct a resource-saving and environmentally friendly society, with the aim of highly coordinated development of the Economic-SocietyEnvironment system in all 7 coastal cities.

\section{Acknowledgements}

The authors thank the financial support of Water Resources Department of Zhejiang Province (RB1922), Educational Department of Zhejiang Province (Y201942916), Key Laboratory of Ecohydrology and Inland River Basin(KLEIRB-ZS-20-04) and the Postdoctors of Zhejiang (ZJ2017134).

\section{Conflict of Interest}

The authors declare that there is no conflict of interest regarding the publication of this paper.

\section{References}

1. GUO A. $13^{\text {th }}$ Five-year Plan Draws up Blueprint for China Economic Development.China's Foreign Trade, 552 (06), 8, 2015.

2. FAN X., ZHAO L., HE D. Land Use Changes and its Driving Factors in a Coastal Zone. Polish Journal of Environmental Studies, 29 (2), 1143, 2020.

3. ZHANG Y., YANG Q., MIN J. An analysis of coupling between the bearing capacity of the ecological environment and the quality of new urbanization in Chongqing. Acta Geographica Sinica, 71 (5), 817, 2016.

4. XIA C., LI Y., YE Y., SHI Z. An integrated approach to explore the relationship among economic, construction land use, and ecology subsystems in Zhejiang province, China. Sustainability, 8 (5), 498, 2016.

5. WANG Q., TANG F. The evaluation of coupling coordination development of ecology-economy-society system in Dongting lake area. Economic Geography, 35 (12), 161, 2015.

6. QIU L., ZHU J.,PAN Y. The positive impacts of landscape fragmentation on the diversification of agricultural production in Zhejiang Province, China. Journal of Cleaner Production, 251, 2020.
7. CASSEN R.H. Our Common Future: Report of the World Commission on Environment and Development. International Affairs, 64 (1), 126, 1987.

8. ARROW K., BOLIN B., COSTANZA R., DASGUPTA P., FOLKE C., HOLLING C.S., JANSSON B.O., LEVIN S., MALER K.G., PERRINGS C., PIMENTEL D. Economicgrowth, carring-capacity, and the environment. Science, 268 (5210), 520, 1995.

9. OSTROM E. A general framework for analyzing sustainability of social-ecological systems. Science, $\mathbf{3 2 5}$ (5939), 419, 2009.

10. GOODLAND R.J.A., DALY H.E., SERAFY S.E. The urgent need for rapid transition to global environmental sustainability. Environmental Conservation, 20 (4), 297, 1993.

11. MIROSLAV S. On sustainability interpretations of the Ecological Footprint. Ecological Economics, 169, 2020.

12. COLLINS A., GALLI A., PATRIZ N. Learning and teaching sustainability: The contribution of Ecological Footprint calculators. Journal of Cleaner Production, 174, 2017.

13. ŚWIADER M., LIN D., SZEWRANSKI S., KAZAK J.K., IHA K., HOOF J.,BELCAKOVA I., AITIOK S. The application of ecological footprint and biocapacity for environmental carrying capacity assessment: A new approach for European cities. Environmental Science and Policy, 56, 2020.

14. GIAMPIETRO M., CERRETELLI G., PIMENTEL D. Energy analysis of agricultural ecosystem managementhuman return and sustainability. Agriculture Ecosystems \& Environment, 38 (3), 219, 1992.

15. HERENDEEN R.A. Ecological network analysis, energy analysis. Encyclopedia of Ecology, 1072, 2008.

16. CRUZ L., IMORI D., FERREIR J.P., GUILHOTO J.J.M., BARATA E., RAMOS P. Energy-Economy-Environment Interactions: A Comparative. Analysis of Lisbon and Sao Paulo Metropolitan Areas. Journal of Environmental Assessment Policy and Management, 21 (2), 2018.

17. LU H., ZHOU L., CHEN Y. Degree of coupling and coordination of eco-economic system and the influencing factors: a case study in Yanchi County, Ningxia Hui Autonomous Region, China. Journal of Arid Land, 9(3), 446, 2017.

18. PENG W., WANG X., LI X. Sustainability evaluation based on the emergy ecological footprint method: A case study of Qingdao, China, from 2004 to 2014. Ecological Indicators, 85, 1249, 2018.

19. ZHANG X., WANG G., WANG Y. Spatial-temporal differences of provincial eco-efficiency in China based on matrix-type network DEA. Economic Geography, 34 (12), 153, 2014.

20. BAI Z., WANG W., LI H. Change of Forest Ecosystem Service Function and Its Value in. Kanas Nature Reserve. Journal of Landscape Research, 11 (06), 80, 2019.

21. DONG S., ZHENG J., LI Y.Quantitative Analysis of the Coupling Coordination Degree Between Urbanization and Eco-environment in Mongolia. Chinese Geographical Science, 29 (05), 861, 2019.

22. ZHAO L., FAN X. Effects of Land Use Changes on Ecosystem Service Values: A Case Study in Guilin, China. Polish Journal of Environmental Studies. 29 (2), 1483, 2020.

23. SU J., HU Z., TANG L. The geographic distribution characters and dynamic evolution for the coordination 
degree of energy-economic-environmental(3E) in China. Economic Geography, 33 (09), 19, 2013.

24. GAO L., GAO Q., SHI L. Research on marine ecoeconomic system coordinated development models in China. Ecological Economy, 30 (2), 105, 2014.

25. ZHOU C., FENG X., TANG R. Analysis and forecast of coupling coordination development among the regional economy-ecological environment-tourism industry-a case study of provinces along the Yangtze economic zone. Economic Geography, 36 (03), 186, 2016.

26. YE M., LI J., SHI X., JIANG Y., SHI Z., XU L., HE G., HUANG R., FENG B. Spatial pattern change of the coastline development and utilization in Zhejiang from 1990 to 2015. Geographical Research, 06, 1159, 2017.

27. LU Y., CHEN Z. Coupling Development of Urbanization and Ecological Economy Environment and Dynamic Quantity in Zhejiang Province. Bulletin of Soil and Water Conservation, 36 (5), 261, 2016.

28. CHINA, N.B.O.S.O. China development report. China Statistics Press: Beijing, 2015.

29. WANG W., SUN L. Coupled Analysis Regional Innovation System and Resource City Industrial Transformation:
A Case Study of Tongling City. Scientia Geographica Sinica, 36 (2), 204, 2016.

30. FANG C., GAO Q., ZHANG X. Spatiotemporal characteristics of the expansion of an urban agglomeration and its effect on the eco-environment: Case study on the northern slope of the Tianshan Mountains. Science China (Earth Sciences), 62 (09), 1461, 2019.

31. MASON D.M. The Hurst phenomenon and the rescaled range statistic. Stochastic Processes and their Applications, 126 (12), 3790, 2016.

32. ZHANG H., KANG C., LI J. R/S analysis of reaction time in Neuron Type Test for human activity in civil aviation. Physica A: Statistical Mechanics and its Applications, 859, 2017.

33. XU J. Mathematical methods in contemporary geography. Higher Education Press: Beijing, 1996.

34. LEE S.J., LEE E.H., AN K.G. Lotic ecosystem health assessments using an integrated analytical approach of physical habitat, chemical water quality, and fish multimetric health metrics. Polish Journal of Environmental Studies, 27 (5), 2113, 2018. 